\title{
Semiological classification of psychogenic nonepileptic seizures.
}

\author{
Ali Akbar Asadi-Pooya \\ Thomas Jefferson University \\ Jennifer Tinker \\ Thomas Jefferson University \\ Elizabeth W. Fletman \\ Thomas Jefferson University
}

Follow this and additional works at: https://jdc.jefferson.edu/neurologyfp

Part of the Neurology Commons

Let us know how access to this document benefits you

\section{Recommended Citation}

Asadi-Pooya, Ali Akbar; Tinker, Jennifer; and Fletman, Elizabeth W., "Semiological classification of psychogenic nonepileptic seizures." (2016). Department of Neurology Faculty Papers. Paper 118.

https://jdc.jefferson.edu/neurologyfp/118

This Article is brought to you for free and open access by the Jefferson Digital Commons. The Jefferson Digital Commons is a service of Thomas Jefferson University's Center for Teaching and Learning (CTL). The Commons is a showcase for Jefferson books and journals, peer-reviewed scholarly publications, unique historical collections from the University archives, and teaching tools. The Jefferson Digital Commons allows researchers and interested readers anywhere in the world to learn about and keep up to date with Jefferson scholarship. This article has been accepted for inclusion in Department of Neurology Faculty Papers by an authorized administrator of the Jefferson Digital Commons. For more information, please contact: JeffersonDigitalCommons@jefferson.edu. 
Title: Semiological classification of psychogenic nonepileptic seizures

Authors: Ali A. Asadi-Pooya, M.D., Jennifer Tinker, Ph.D., Elizabeth Fletman

Jefferson Comprehensive Epilepsy Center, Department of Neurology, Thomas Jefferson

University, Philadelphia, Pennsylvania, PA, USA.

Address for correspondence:

Ali A. Asadi-Pooya, M.D.

Department of Neurology

901 Walnut Street, Suite 435

Philadelphia, PA 19107

Phone: $215-955-1222$

Fax: 215-955-3745

E-mails: aliasadipooya@yahoo.com; jennifer.tinker@jefferson.edu;

Elizabeth.Fletman@jefferson.edu

Running title: Semiological classification of psychogenic nonepileptic seizures

Number of characters in the title: 64; number of characters in the running head: 64; number of text pages: 7; number of words: 1754; number of words in the abstract: 238 ; number of references: 13; number of figures: 0 ; number of tables: 1 . 


\begin{abstract}
Purpose: We classified patients with psychogenic nonepileptic seizures (PNES) according to a newly proposed classification system. Then, we investigated the demographic and clinical differences between various classes of the patients.

Methods: We retrospectively investigated all patients with PNES admitted at the Jefferson Comprehensive Epilepsy Center from 2012 through 2016. We classified the patients into four distinct classes: generalized motor, akinetic, focal motor, and patients with subjective symptoms. All patients were interviewed by a neuropsychologist and were administered psychological assessment measures, including questions about PNES risk factors. For the statistical analyses, we compared patients who had generalized motor seizures with patients who had non-motor seizures.
\end{abstract}

Results: Sixty three patients were studied. Thirty five (55.6\%) patients had generalized motor seizures, $14(22.2 \%)$ had seizures with subjective symptoms, 12 (19\%) had akinetic seizures, and two $(3.2 \%)$ patients had focal motor seizures. Patients with generalized motor seizures (35 patients) demonstrated a trend for later age at onset $(\mathrm{p}=0.06)$, more frequently had a history of substance abuse $(\mathrm{p}=0.001)$, and more often had loss of responsiveness with their seizures $(\mathrm{p}=$ 0.04) compared with patients who had non-motor seizures (26 patients).

Conclusion: The recently proposed PNES classification system is a useful and practical proposal. This proposed classification of PNES may address proper diagnosis and provide standardization across future studies. This may also potentially shed light on the etiologic understanding and management process of various classes of patients affected with PNES.

Key words: Classification; PNES; Psychogenic; Seizure; Semiology 


\section{Introduction}

Psychogenic non-epileptic seizures (PNES) are relatively common occurrences in epilepsy centers ${ }^{1}$. However, PNES is a unique condition in that it is largely defined in terms of what it is not rather than what it is. Successful exclusion of other differential diagnoses (e.g., epilepsy) does little to define the variables that might affect the management process of these patients. Recently, some experts tried to provide various classification systems for PNES ${ }^{2-6}$. A semiologically focused classification of PNES may address proper diagnosis and provide standardization across future studies ${ }^{2}$. However, it is unclear whether such a classification system can contribute to our etiologic understanding and management of patients with PNES. In the current study, we first classified patients with PNES according to a newly proposed classification system ${ }^{2}$ to evaluate its practicality. Then, we investigated the demographic and clinical differences between various groups of patients with PNES based on this classification system. This may potentially shed light on the etiologic understanding and management process of various groups of patients affected with PNES.

\section{Methods}

In this retrospective study, we investigated all patients with PNES admitted to the epilepsy monitoring unit at the Jefferson Comprehensive Epilepsy Center from 2012 through 2016. Patients with a confirmed diagnosis of PNES were included. The diagnosis was determined by the clinical assessment and long-term video-EEG monitoring with ictal recording. The epileptologists and neuropsychologists interviewed all of the patients. Patients with concomitant epilepsy, abnormal EEG (e.g., ictal or interictal epileptiform discharges), or incomplete data (e.g., historical or psychiatric data) were not included. 
We reviewed at least one episode of PNES that was recorded during the video-EEG monitoring and was typical of the patient's habitual seizures (based on their history) in each patient. We classified the patients into four distinct classes ${ }^{2}$ : generalized motor, akinetic, focal motor, and with subjective symptoms. These classes were defined as follows ${ }^{2}$ :

1. Generalized motor: seizures mainly characterized by tonic, clonic, or dystonic generalized movements, tremors, rigor-like movements, whole body rigidity, pelvic thrusting, pedaling, and/or side to side head movements.

2. Akinetic: seizures mainly characterized by unresponsiveness and the absence of movement. Minor distal limb tremors were permitted.

3. Subjective symptoms: seizures were mainly characterized by experiential phenomena reported by the patients. Eyelid myoclonia and minor distal limb tremors were permitted.

4. Focal motor: seizures with focal motor movements.

All studied patients were administered psychological self-report inventories (i.e., Beck Depression Inventory and Beck Anxiety Inventory) as well as a separate questionnaire examining some of the known risk factors for PNES including sexual abuse, physical abuse, history of head trauma, and family history of seizures. Other clinical and demographic variables were gleaned from the medical records. Demographic variables and relevant clinical variables were summarized descriptively to characterize the study population and subgroups of patients with PNES. Pearson Chi-Square, t- test, and Kolmogorov-Smirnov test were used for statistical analyses. P value less than 0.05 was considered significant. This study was conducted with the approval by Thomas Jefferson University Institutional Review Board. 


\section{Results}

Sixty three patients were studied. Age range of the patients was 14-92 years (39 \pm 16 years). Age at the onset of the seizures was $34 \pm 16$ years (range 12-91 years) and disease duration before diagnosis was $5 \pm 7$ years (range $0-40$ years). Thirty five $(55.6 \%)$ patients had generalized motor seizures, 14 (22.2\%) had seizures with subjective symptoms, $12(19 \%)$ had akinetic seizures, and two $(3.2 \%)$ patients had focal motor seizures. For the statistical analyses, we excluded those two patients with focal motor seizures and compared patients with generalized motor seizures (35 patients) with patients in the other classes (i.e., patients with akinetic seizures and those with subjective symptoms, who had non-motor seizures) (26 patients). Table 1 shows the demographic and clinical variables among patients with generalized motor seizures compared with those with non-motor PNES. There was a trend for later age at onset among patients with generalized motor PNES compared to those who had non-motor PNES. In addition, patients with generalized motor PNES more frequently reported substance abuse compared to those who had non-motor PNES. Finally, patients with generalized motor PNES more often reported loss of responsiveness associated with their seizures compared to those who had non-motor PNES. When we classified the two patients who had focal motor seizures and patients with generalized motor seizures as one class (as patients with motor PNES; 37 patients) and compared these with patients who had non-motor PNES (26 patients), similar results (as in Table 1) were observed.

\section{Discussion}

In this study, we observed that the recently proposed classification system of PNES ${ }^{2}$ is a practical and clinically applicable system. This classification system proved to be valid and reliable in its original study ${ }^{2}$. According to this semiological classification system of PNES, we 
observed that more than half of our patients had generalized motor seizures, while approximately two-fifths had non-motor seizures. Focal motor seizures were not common in our patient population. This is concordant with that previous study in which $44 \%$ of their patients had hypermotor seizures (equivalent to generalized motor seizures in our study), $24 \%$ had akinetic seizures, $24 \%$ had subjective symptoms, and $9 \%$ had focal motor seizures ${ }^{2}$. A previous study revealed similar results ${ }^{5}$. We preferred the term generalized motor to hypermotor because hypermotor often implies complex large movements involving the trunk and proximal segments of the limbs ${ }^{7}$, and this is not always the case in patients with PNES characterized by generalized motor seizures (e.g., in those with tonic or dystonic seizures).

When we compared patients with generalized motor seizures with those patients with non-motor PNES, we observed that the former group demonstrated a trend towards a later age at onset. In a previous study ${ }^{5}$, major motor activity was the main feature in adults with PNES, while minor motor activity was more prevalent among children, which is concordant with our observations. According to the evidence provided by imaging studies for the neurobiological origin of PNES, an abnormal connectivity between brain areas involved in emotional evaluation and responses, cognitive integration systems, and motor regions is suggested to explain the ictal events seen in patients with PNES ${ }^{8}$. It is possible that brain connectivity is differently disturbed in patients with early-onset PNES compared with that in patients with later-onset disease. Therefore, they present with different seizure semiology. This hypothesis should be tested in future studies. In addition, different patients with PNES have different underlying defense mechanisms and can also have different coping strategies ${ }^{9}$. Therefore, it is quite possible that different patients show different reactions and behaviors (i.e., seizure semiology) in response to similar emotional problems. 
The relationship between sexual abuse and PNES has received particular attention in the literature. In one study of comparison of patients with PNES only (324 patients) with those who had epilepsy (281 patients), a history of abuse (physical or sexual) was more frequent among those with PNES [Odds ratio: $3.35(1.23-9.10) ; \mathrm{P}=0.018{ }^{10}$. Similarly, data suggests that compared with patients with epilepsy, those with PNES have more psychiatric comorbidity (RR: $1.30,95 \%$ CI: $1.14-1.48, \mathrm{p}=0.0001)^{11}$. We did not identify a relationship between a history of abuse (physical or sexual) or mental health problems with various PNES classes. However, we did observe that a history of substance abuse is more frequent among patients with generalized motor seizures compared with that in patients with non-motor PNES. Previous studies reported the prevalence of alcohol and substance abuse in patients with PNES to be between $9.8 \%$ and $29.5 \%{ }^{11}$. We observed that $31 \%$ of the patients with generalized motor PNES reported substance abuse, whereas none of the patients with non-motor PNES had such a history. A previous review suggested that brain circuit connectivity may explain specific neurobiological substrates underlying psychological dysfunctions associated with reward, affective and cognitive processing often observed in drug addiction ${ }^{12}$. The temporal relationship between substance abuse and onset of PNES in our patients remains unknown and therefore, we cannot establish a causal relationship. However, we may hypothesize that brain connectivity is differently disturbed among patients with generalized motor seizures compared with that in patients with non-motor PNES; hypothetically, this may predispose the patients for substance abuse (or vice versa). Welldesigned fMRI studies may help identify the differences between functional brain connectivity in patients with various forms of PNES ${ }^{13}$; this may provide insight into potential treatment paradigms. 
Finally, we observed that generalized motor PNES is more often associated with loss of responsiveness compared with that in patients with non-motor seizures. We did not study the consequences of various forms of PNES in this study; however, one can safely assume that patients who have generalized motor PNES and loss of responsiveness are more likely to seek emergency medical treatment (both because of its violent presentation and also the associated loss of responsiveness) and are therefore at increased risk for iatrogenic harm (e.g., IV medications, intubation, and other procedures). This has important clinical implications both for the patients and also for health care professionals. It would be very interesting to study the relationship between prognosis and PNES semiology.

In conclusion, we observed that the recently proposed PNES classification system by Magaudda, et al. ${ }^{2}$ is a useful and practical proposal and may provide a good foundation to begin discussions on the definition and classification of PNES in the scientific community. This proposed classification of PNES may address proper diagnosis and provide standardization across future studies and may also potentially shed light on the etiologic understanding and management process of various classes of patients affected with PNES.

Our study has some limitations. This was a retrospective study and patient data and review of ictal EEGs came from a single institution. We reviewed at least one episode of PNES that was typical of the patient's habitual seizures in each patient. Many patients with PNES do not have one stereotypical seizure behavior. However, most patients have more or less similar seizures and witnesses can often identify a habitual seizure when asked to do so (when we review the recorded video of the PNES with them). Finally, we did not investigate other possible risk factors for PNES in this study (other than sexual abuse, physical abuse, history of head trauma, and family history of seizures). 


\section{Acknowledgment}

This was an unfunded study.

\section{Disclosures}

Ali A. Asadi-Pooya, M.D., consultant: Cerebral Therapeutics, LLC and UCB Pharma. Jennifer Tinker, $\mathrm{PhD}$. and Elizabeth Fletman report no conflict of interest.

\section{Contributions}

Ali A. Asadi-Pooya, M.D.: Study design, data collection, statistical analysis, manuscript preparation. Jennifer Tinker, Ph.D. and Elizabeth Fletman: data collection and manuscript preparation. 


\section{References}

1. Asadi-Pooya AA, Sperling MR. Epidemiology of psychogenic non-epileptic seizures. Epilepsy Behav 2015; 46:60-65.

2. Magaudda A, Laganà A, Calamuneri A, Brizzi T, Scalera C, Beghi M, et al. Validation of a novel classification model of psychogenic nonepileptic seizures by video-EEG analysis and a machine learning approach. Epilepsy Behav 2016; 60: 197-201.

3. Hubsch C, Baumann C, Hingray C, Gospodaru N, Vignal JP, Vespignani H, et al. Clinical classification of psychogenic non-epileptic seizures based on video-EEG analysis and automatic clustering. J Neurol Neurosurg Psychiatry 2011; 82(9): 955-960.

4. Dhiman V, Sinha S, Rawat VS, Harish T, Chaturvedi SK, Satishchandra P. Semiological characteristics of adults with psychogenic nonepileptic seizures (PNESs): an attempt towards a new classification. Epilepsy Behav 2013; 27(3): 427-432.

5. Alessi R, Vincentiis S, Rzezak P, Valente KD. Semiology of psychogenic nonepileptic seizures: age-related differences. Epilepsy Behav 2013; 27(2): 292-295.

6. Wadwekar V, Nair PP, Murgai A, Thirunavukkarasu S, Thazhath HK. Semiologic classification of psychogenic non epileptic seizures (PNES) based on video EEG analysis: do we need new classification systems? Seizure 2014; 23(3): 222-226.

7. Tufenkjian K, Lüders HO. Seizure semiology: its value and limitations in localizing the epileptogenic zone. J Clin Neurol 2012; 8(4): 243-250.

8. Asadi-Pooya AA. Neurobiological origin of psychogenic nonepileptic seizures: A review of imaging studies. Epilepsy Behav 2015; 52(Pt A): 256-259. 
9. Beghi M, Negrini PB, Perin C, Peroni F, Magaudda A, Cerri C, et al. Psychogenic nonepileptic seizures: so-called psychiatric comorbidity and underlying defense mechanisms. Neuropsychiatr Dis Treat 2015; 11: 2519-2527.

10. Elliott JO, Charyton C. Biopsychosocial predictors of psychogenic non-epileptic seizures. Epilepsy Res 2014; 108(9): 1543-1553.

11. Diprose W, Sundram F, Menkes DB. Psychiatric comorbidity in psychogenic nonepileptic seizures compared with epilepsy. Epilepsy Behav 2016; 56: 123-30.

12. Sutherland MT, McHugh MJ, Pariyadath V, Stein EA. Resting state functional connectivity in addiction: Lessons learned and a road ahead. Neuroimage 2012; 62(4): 2281-2295.

13. Asadi-Pooya. An fMRI study to identify the neurobiological link between sex abuse and psychogenic nonepileptic seizures. Epilepsy Behav 2016; 57(Pt A): 222. 
Table 1. Demographic and clinical variables among patients with generalized motor PNES compared with those with non-motor PNES *.

\begin{tabular}{|c|c|c|c|}
\hline Variable & $\begin{array}{c}\text { Patients with } \\
\text { generalized } \\
\text { motor PNES (35) }\end{array}$ & $\begin{array}{l}\text { Patients with } \\
\text { non-motor } \\
\text { PNES (26) }\end{array}$ & $\begin{array}{c}\mathbf{P} \\
\text { value }\end{array}$ \\
\hline Sex (female : male) & $28: 7$ & $21: 5$ & 1 \\
\hline Age (mean \pm standard deviation) (years) & $42 \pm 17$ & $35 \pm 15$ & 0.1 \\
\hline Age at onset (mean \pm standard deviation) (years) & $37 \pm 17$ & $29 \pm 13$ & 0.06 \\
\hline Disease duration (mean \pm standard deviation) (years) & $4.5 \pm 5.7$ & $6 \pm 9.9$ & 0.4 \\
\hline Education (mean \pm standard deviation) (years) & $13 \pm 2$ & $14 \pm 3$ & 0.6 \\
\hline Family history of seizures & $12(34 \%)$ & $7(27 \%)$ & 0.7 \\
\hline History of head trauma & $11(31 \%)$ & $6(23 \%)$ & 0.3 \\
\hline History of physical abuse & $14(40 \%)$ & $8(30 \%)$ & 0.5 \\
\hline History of sexual abuse & $14(40 \%)$ & $5(19 \%)$ & 0.1 \\
\hline History of substance abuse & $11(31 \%)$ & 0 & 0.001 \\
\hline History of alcohol abuse & $3(9 \%)$ & 0 & 0.2 \\
\hline Full scale IQ (mean \pm standard deviation) & $90 \pm 19$ & $96 \pm 14$ & 0.2 \\
\hline Beck depression score (mean \pm standard deviation) & $16 \pm 11$ & $16 \pm 12$ & 1 \\
\hline Beck anxiety score (mean \pm standard deviation) & $19 \pm 12$ & $19 \pm 14$ & 0.8 \\
\hline Associated loss of responsiveness & $29(83 \%)$ & $15(58 \%)$ & 0.04 \\
\hline
\end{tabular}

*Some data were missing. PNES: psychogenic nonepileptic seizures. 